\title{
RISK METHODS AND THEIR APPLICATIONS IN AGRICULTURE
}

\author{
M. LADÁNYI \\ Corvinus University of Budapest, Department of Mathematics and Informatics, \\ 1118 Budapest Villányi út 29-35, Hungary \\ e-mail:marta.ladanyi@uni-corvinus.hu \\ (Received $15^{\text {th }}$ April 2007; accepted $14^{\text {th }}$ December 2007)
}

\begin{abstract}
In agriculture we face several decision problems in which, among proficiency and sustainability, the risk aspects have to be investigated more and more seriously. In Hungary the risk of production is especially meaningful as it has considerably been increased in the last few decades. In this paper we review those risk analysis methods which are very useful in climate change impact research. We give a case study of the application of the described methods in which we prove that the risk of corn and wheat production has increased between 1951 and 1990 in four Hungarian regions (Hajdú-Bihar, BácsKiskun, Fejér and Györ-Moson-Sopron), independently to the rate of absolute risk aversion. In some regions the rate of increase became even quicker.
\end{abstract}

Keywords: risk of production, Phillips-method, efficiency criteria, climate change, decision analysis

\section{Introduction}

Considering risk in agriculture is nowadays more necessary than ever. With climate change the consequences of all decisions are becoming more and more serious, especially in agricultural production. In this paper we review some results and give a case study.

\section{Review of literature}

Risk analysis is quite a young discipline, the base of which was established by Knight, in 1933. After some decades the structure of risk analysis was very similar in the books of Raiffa (1968) and Schlaifer $(1959,1969)$. Risk analysis started to improve dinamically in the end of the 70s which can be noticed in the books of the 80s with the main principles of the field (Barry (1984), Lindley (1985), Robison and Barry (1987), illetve Gregory (1988)). In some works the risk of agriculture is considered with high relevance (Halter and Dean (1971), Dillon (1971)).

Risk analysis is surveyed with deep mathematical tools in Spetzler and von Holstein (1975), Smith (1988), Smith and Mandac (1995) and Pratt et al. (1995).

The book of Anderson et al. (1977) is mighty comprehensive with several agricultural applications and the operation research aspects are considered as well.

In Clemen (1996) a general description of modern risk analysis with data management and decision analysis can be found.

Just (2003) gives an outlook to the possible improvements in the following 25 years, especially with respect of agricultural risk.

The book of Hardaker et al. (2004) is an excellent monography in which there is a special emphasis on agricultural risk. 


\section{Notations}

Let us denote one of the decisions, between which the decision maker (DM) must choose by $a_{j}$ ( $a_{j} \in A$, the set of possible choices), the uncertain states of nature by $S_{i}$ ( $i \in I, j \in J, I$ and $J$ are sets of indexes) and their (subjective) probability with $P\left(S_{i}\right)$. The consequencies of the jth act supposed the state $S_{i}$ are denoted by $X_{i j}$.

\section{The axioms of decision analysis}

Let us accept the following version of the axioms of decision analysis as the base of our survey (Anderson et al., 1977):

There is an ordering $<$ on the set $A$, namely if $a_{1}, a_{2} \in A$ then exactly one of the following holds:

$$
a_{1}<a_{2} \quad a_{2}<a_{1} \quad a_{1}=a_{2}
$$

where $a_{1}<a_{2}$ means that the DM prefers $a_{2}, a_{1}=a_{2}$ means that the DM is indifferent between the two decisions.

The relation $<$ is transitive.

The relation $<$ is continuous. If $a_{1}<a_{2}<a_{3}$, then there exists $0<P\left(a_{1}\right)<1$ and $P\left(a_{3}\right)=1-P\left(a_{1}\right)$ such that $a_{1}=a_{2}=a_{3}$ with these subjective probabilities.

The relation $<$ is independent. If $a_{1}<a_{2}$ with $P\left(a_{1}\right)=P\left(a_{2}\right)$, then for any other $a_{3} \in A:\left(a_{1} \operatorname{AND} a_{3}\right)<\left(\begin{array}{lll}a_{2} & \operatorname{AND} a_{3}\end{array}\right)$.

With the help of the above axioms the Bernoulli's principles (1738) can be formulated. (Also called by the subjective expected utility - SEU - hypothesis.)

Under the conditions of the above axioms there exists a utility function $U: A \rightarrow \mathbf{R}$ for which

If $a_{1}, a_{2} \in A \quad a_{1}<a_{2}$ holds, then $U\left(a_{1}\right)<U\left(a_{2}\right)$.

The DM's utility function can be expressed as the function of the decisions:

$U\left(a_{j}\right)=\sum_{i} U\left(a_{j} \mid S_{i}\right) \cdot P\left(S_{i}\right)$ for discrete probability;

$U\left(a_{j}\right)=\int U\left(a_{j} \mid S\right) \cdot P(S) d S$ for continuous probability);

or as the function of the certainty equivalent of the decisions $\left(C E_{j}\right)$ :

$U\left(a_{j}\right)=U\left(C E_{j}\right)$.

Certainty equivalent is the value "for sure" that would make the DM indifferent to facing the risky prospect or to accept the value "for sure" with $\min _{i}\left(X_{i j}\right)<C E_{j}<\max _{i}\left(X_{i j}\right)$ (Hardaker et al., 2004).

The function $U$ is invariant to a positive linear transformation.

Based on the above axioms and principles risk analysis can be structured in an exact way (Savage, 1954, Edwards, 1992, Quiggin, 1993).

\section{General problems of data management}

In several cases one of the main problems in agricultural surveys that there is no available data of necessary quality and/or quantity. The problem has its objective 
reasons: detailed and unique monitoring and data management do not have a long history.

In case of sparse data we need to think over thoroughly how we can get the most information from the few data. One of the most evident ways of gaining more information is to take experts' opinion into consideration.

\section{Relative frequency contra subjective probability}

In classical probability it is mostly assumed that abundant and relevant data are available (theoretically an infinite number of possible experiments). In these cases the use of relative frequency to estimate probability is quite evident. It occurs several times in agricultural surveys, however, that probability estimations for such kinds of events are needed that

- happen quite rarely (e.g. catastrophes) or

- are changing in time not accidentally (prices).

In these occasions relative frequency estimations are not suitable.

In the recent past a new school of thought has developed. According to this, a probability can be defined as the 'degree of belief' (called subjective probability) which is mainly based on experts' estimations. This kind of estimation is, of course, subjective, though experience has proved its relevancy (Wright and Ayton, 1994, Phillips, 1971).

Subjective probability and the way of defining the distribution function from it have both widely applied literatures (Raiffa, 1968, Anderson, Dillon and Hardaker, 1977, Lindley, 1985, Clemen, 1996).

\section{Elicitation of the distribution function in case of sparse data}

The judgemental fractile method is based on subjective experts' estimations (Hardaker et al., 2004). First, we ask our respondent to estimate the range of the distribution $\left(x_{0}, x_{n+1}\right)$. Further on it is supposed that $F(x)=0$, if $x \leq x_{0}$ and $F(x)=1$, if $x>x_{n+1}$. Next the interval $(0,1)$ should be divided into $n+1$ parts:

$$
y_{i}:=\frac{i}{n+1} \quad(i=0,1, \ldots, n+1)
$$

and the following values of the distribution functions are asked to be estimated: $F\left(x_{i}\right)=y_{i} \quad(i=0,1, \ldots, n+1)$. The estimated points of the distribution function can be approximated and smoothed with other known methods.

\section{Phillips-method}

If historical data are available it is reasonable to use them combined with subjective judgements. Phillips (1971) has given a smart method for the case when the data are obsolete and thus not relevant for future conclusions any more. The method involves the following steps:

First, the subjective mean and standard deviation of the subjective distribution have to be elicited. To this several known estimations can be used, e.g. the triangular distribution method: $E_{\mathrm{s}}=\frac{a+b+m}{3}, D_{\mathrm{s}}=\frac{(b-a)^{2}+(m-a)(m-b)}{18}$. 
where $a, b$ and $m$ are the highest, the lowest and the most likely values of the distribution, respectively.

Next, the historical data have to be corrected with trend. To this we can apply an appropriate regression function $f$ with residuals $\varepsilon_{i}=y_{i}-f\left(x_{i}\right)$. Then the corrected data can be defined as

$\hat{y}_{i}=f\left(x_{\text {curr }}\right)+\varepsilon_{i}$

where $f\left(x_{\text {curr }}\right)$ denotes the current regression value taken in the most current point $x_{\text {curr }}$.

The values $\hat{y}_{i}$ should be weighted with appropriate probabilities $p_{i}$ assessed by considering the current likelihoods of the occurrences of the adequate conditions in the past. If there is no basis for such assignment, all $p_{i}$ should be chosen equally. Obviously $\sum_{i} p_{i}=1$.

The mean and standard deviation have to be defined with the help of the weighted corrected data: $E=\sum_{i} p_{i} \hat{y}_{i}, D=\sqrt{\sum_{i} p_{i}\left(\hat{y}_{i}-E\right)^{2}}$.

The data adequate for the further survey are then: $Y_{i}=E_{\mathrm{s}}+\frac{\hat{y}_{i}-E}{D} \cdot D_{\mathrm{s}}$. It is easy to see that $E\left(Y_{i}\right)=E_{\mathrm{s}}$ and $D\left(Y_{i}\right)=D_{\mathrm{s}}$.

\section{Risk aversion}

It is evident that most of DMs are risk averse. If they can choose between two decisions with the same expected mean, they would choose the one which is less risky. This aversion to risk has to seriously be taken into account while preparing decisions.

Considering risk aversion we can define the utility ordering amongst decisions much more precisely.

\section{Utility function elicitation}

Utility function $U$ can be elicited in several ways. We call for the socalled ELCE (Equally Likely Certainty Equivalent) method due to Anderson et al. (1977). Let us use the following notations: $\left(a_{1}, a_{2}, \ldots\right)$ are decisions with a set of possible payoffs $\left(X_{1}, X_{2}, \ldots\right)$ with probabilities $\left(p_{1}, p_{2}, \ldots\right)$, shortly $\left(X_{1}, X_{2}, \ldots ; p_{1}, p_{2}, \ldots\right)$. We denote by $\sim$ the DM's indifference between the risky decisions $\left(a_{1}, a_{2}, \ldots\right)$ and the sure one $a_{s}$ : $\left(X_{1}, X_{2}, \ldots ; p_{1}, p_{2}, \ldots\right) \sim\left(X_{s} ; 1\right)$.

The sequence of the elicitation is as follows:

- Let us denote by $a$ the lowest and by $b$ the highest payoff of interest. Then we say that $U(a)=0$ and $U(b)=1$.

- Estimate $c$ such that $(a, b ; 0.5,0.5) \sim(c ; 1)$. Then we get $U(c)=0.5 \cdot U(a)+0.5 \cdot U(b)=0.5$. 
- Estimate $d$ and $e$ such that $(a, c ; 0.5,0.5) \sim(d ; 1)$ and $(c, b ; 0.5,0.5) \sim(e ; 1)$. Then we get $U(d)=0.5 \cdot U(a)+0.5 \cdot U(c)=0.25$ and

$$
U(e)=0.5 \cdot U(c)+0.5 \cdot U(b)=0.75 .
$$

- Estimate $f$ such that $(d, e ; 0.5,0.5) \sim(f ; 1)$. Then we get $U(f)=0.5 \cdot U(d)+0.5 \cdot U(e)=0.5$.

Of course, we can go on with the method as long as we gain so many points that are needed to reach the necessary accuracy. Finally, we plot the points of the utility function (Fig. 1). The so called ELRO method (Equally Likely Risky Outcomes) is quite similar to the ELCE one with the difference that in this method those pairs of values $c, d$ are elicited for which $(a, d ; 0.5,0.5) \sim(b, c ; 0.5,0.5)$. For the detailed advantages and disadvantages of these two methods, moreover, for a comparison of ELCE and ELRO methods one can see Hardaker et al. (2004).

$$
\begin{aligned}
& U(a)=0 \text { and } U(b)=1 \\
& (a, b ; 0.5,0.5) \sim(c ; 1) \\
& \quad \Rightarrow U(c)=0.5 \\
& (a, c ; 0.5,0.5) \sim(d ; 1) \\
& \quad \Rightarrow U(d)=0.25 \\
& \quad(c, b ; 0.5,0.5) \sim(e ; 1) \\
& \quad \Rightarrow U(e)=0.75 \\
& (d, e ; 0.5,0.5) \sim(f ; 1) \\
& \quad \Rightarrow U(f)=0.5
\end{aligned}
$$

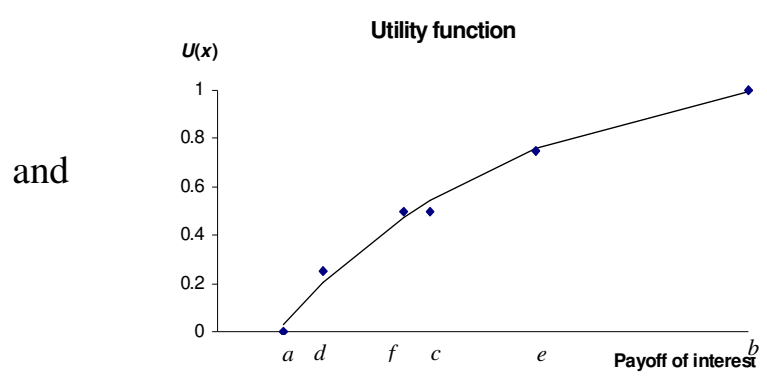

Figure 1. Utility function elicitation with ELCE method. Decision depends not only on possible payoffs but also on the DM's risk aversion. Considering risk aversion we can define the utility ordering amongst decisions much more precisely.

\section{Absolute and relative risk aversion}

The shape of utility function $U$ gives further information on risk aversion. Generally, the DM is risk averse if the utility function is concave and prefers risk if $U$ is convex. The greater the absolute value of the second derivative of $U$ is the greater the risk averse is.

The absolute risk aversion $r_{a}(w)$ and the relative risk aversion $r_{r}(w)$ are defined by

$$
r_{a}: \mathbf{R} \rightarrow \mathbf{R} w \mapsto r_{a}(w)=-\frac{U^{(2)}(w)}{U^{(1)}(w)} \quad r_{r}: \mathbf{R} \rightarrow \mathbf{R} w \mapsto r_{r}(w)=w r_{a}(w)
$$

where $w$ is for wealth (Pratt, 1964, Arrow, 1965).

Anderson and Dillon (1992) provides a classification for relative risk aversion (Table 1).

Table 1. Classification for relative risk aversion due to Anderson and Dillon (1992)

\begin{tabular}{|c|c|c|c|c|c|}
\hline$r_{r}(w)$ & 0.5 & $\mathbf{1 . 0}$ & 2.0 & 3.0 & 4.0 \\
\hline The rate of risk aversion & low & normal & high & very high & extrem high \\
\hline
\end{tabular}


Hardaker et al. (2004) reformulate the above classification with using the rate of the maximum percent of the current wealth which is ready to be steaked if there is $50 \%$ chance to increase it by $20 \%$ (Table 2 ).

Table 2. Classification for relative risk aversion due to Hardaker et al. (2004)

\begin{tabular}{|c|c|c|c|c|c|c|}
\hline Maximum stake percent of wealth & $20 \%$ & $18 \%$ & $\mathbf{1 7 \%}$ & $14 \%$ & $12 \%$ & $11 \%$ \\
\hline$r_{r}(w)$ & 0.0 & 0.5 & $\mathbf{1 . 0}$ & 2.0 & 3.0 & 4.0 \\
\hline
\end{tabular}

There are different categories of risk aversion depending on how it is changing with increasing wealth (Eeckhoudt and Gollier, 1966, Hamal and Anderson, 1982) (Table 3).

Table 3. Categories of risk aversion according to how it changes with increasing wealth

\begin{tabular}{|c|c|c|}
\hline \multicolumn{3}{|c|}{ If $w$ wealth is increasing then } \\
\hline \multirow{3}{*}{$r_{a}$} & increasing & IARA (Increasing Absolute Risk Aversion) \\
\hline & constant & CARA (Constans Absolute Risk Aversion) \\
\hline & decreasing & DARA (Decreasing Absolute Risk Aversion) \\
\hline \multirow{3}{*}{$r_{r}$} & increasing & IRRA (Increasing Relative Risk Aversion) \\
\hline & constant & CRRA (Constans Relative Risk Aversion) \\
\hline & decreasing & DRRA (Decreasing Relative Risk Aversion) \\
\hline
\end{tabular}

Table 4 shows some generally applied utility functions. They are widely used especially when there is no way to consult with the DM, thus his personal utility function can not be elicited.

Table 4. The mostly applied general utility functions

\begin{tabular}{|c|c|c|c|c|}
\hline $\begin{array}{c}\text { CARA/ } \\
\text { CRRA }\end{array}$ & $\begin{array}{c}\text { Negative } \\
\text { exponential }\end{array}$ & $U: w \mapsto 1-\exp (-c w)$ & $r_{a}(w)=c$ & $r_{r}(w)=c w$ \\
\hline \multirow{2}{*}{$\begin{array}{c}\text { CRRA/D } \\
\text { ARA }\end{array}$} & Logarithmic & $U: w \mapsto \ln w w>0$ & $r_{a}(w)=1 / w$ & $r_{r}(w)=1$ \\
\cline { 2 - 5 } & Power & $U: w \mapsto[1 /(1-r)] w^{1-r} w>0$ & $r_{a}(w)=r / w$ & $r_{r}(w)=r$ \\
\hline
\end{tabular}

The mostly used utility function is the logarithmic one which is postulated by D. Bernoulli (1738). For more interesting and useful utility functions see Farquhar and Nakamura (1987), Nakamura (1996), Bell (1988) ands Saha (1993).

Note that risky outcomes can be expressed not only in terms of wealth but also of gains or losses (Hardaker, 2004, Meyer, 2001).

Hardaker et al. (2004) and Pannel et al. (2000) analyse in which cases risk aversion is reasonable to be taken account and in which cases it can be neglected (see also Anderson and Hardaker, 2003 and Hardaker, 2000).

As utility functions are invariant (SEU hypothesis 4), the utility functions due to different persons are not comparable. From this the so called Impossibility Theorem was deduced by Arrow (1963): in the case of group decision there no utility function exists without violating some conditions of the individual DMs. For the suitable handling of this problem, see Raiffa (1968) as well as Anderson, Dillon and Hardaker (1977). 


\section{Efficiency criteria}

\section{E, $V$-efficiency criterion}

$E, V$-efficiency criterion is based on a very simple proposition, namely if there are two decisions $a_{1}$ and $a_{2}$ with $E_{1} \geq E_{2}$ and $V_{1} \leq V_{2}$ (where at least one of the relations is strict), than $a_{1}>a_{2}$, that is to say the DM prefers $a_{1}$ to $a_{2}$. The criterion is exact if the DM has a normal outcome distribution and a quadratic utility function which is usually not the case. Thus, $E$, $V$-efficiency criterion should be used as an approximate rule, only. Moreover, in most cases there is no entire ordering between the alternatives. As it is very straightforward and does not need much information, however, it can be applied with success when a great set of decisions should be reduced. That's why the criterion is very popular in practice (Hardaker et al., 2004).

The mean and the variation of the distribution have to be calculated and plotted.

$$
\begin{aligned}
& E=\sum_{i}\left(F_{i+1}-F_{i}\right) \frac{\left(x_{i+1}+x_{i}\right)}{2}, \\
& V=\sum_{i}\left(F_{i+1}-F_{i}\right) \frac{x_{i+1}^{2}+\left(x_{i+1} x_{i}\right)^{2}+x_{i}^{2}}{3}-E^{2} .
\end{aligned}
$$

$a_{1}>a_{2}$ if the $E, V$ point of $a_{2}$ lies in the 'north-west' quadrant of the $E, V$ point of $a_{1}$. If there is no point lying in the 'north-west' quadrant of an $E, V$ point, then we say that it belongs to the $E, V$ efficient set, that is to say, the point belongs to 'one of the best alternatives'.

\section{A criterion based on the utility function}

Let us set out from a negative exponential utility function $U: w \mapsto 1-\exp (-c w)$. In order to estimate the certainty equivalent $C E$, we take the Taylor series expansion of the utility function in a region of the mean (Freund, 1956): $C E=E-0.5 \mathrm{cV}$. From this we get the approximated functions $U_{i}: V_{i} \mapsto E_{i}-0.5 r_{a} V_{i}$ for each alternative where $r_{a}$ denotes the absolute risk aversion constant. Illustrate the utility functions for fixed $C E$ values: $U_{i, C E}: V_{i} \mapsto C E+0.5 r_{a} V_{i}$ that we call indifference curves. According to the criterion based on the utility function, the best alternative for a fixed degree of absolute risk aversion lies on the highest indifference curve (with the greatest value of $C E$ ).

\section{Stochastic dominance}

$a_{1}$ and $a_{2}$ are two alternatives with probability distributions $F_{1}$ and $F_{2}$, respectively. We say that $a_{1}>a_{2}$ ( $a_{1}$ dominates $a_{2}$ in first-degree sense) if $F_{1}(x) \leq F_{2}(x) \quad(x \in \mathbf{R})$ and there is a strict inequality at least in one point $x$. The disadvantage of the first-degree stochastic dominance is that in most cases the distribution functions cross each other which means, that there is no ordering between the alternatives. The rule is, however, suitable for alternative set reducing, again, like $E, V$ efficiency criterion.

Having a smaller alternative set we can go on with the second-degree stochastic dominance which can be applied if the conditions for the first and second derivatives of the utility function $U^{(1)}>0$ and $U^{(2)}<0$ hold. Then $a_{1}>a_{2}\left(a_{1}\right.$ dominates $a_{2}$ in 
second-degree sense), if $\int_{-\infty}^{x} F_{1}(t) d t \leq \int_{-\infty}^{x} F_{2}(t) d t(x \in \mathbf{R})$ with a strict inequality at least in one point $x$.

There are examples in the literature when third-degree dominance is used, nevertheless there is a reasonable doubt whether it is really useful (Anderson et al., 1977).

Stochastic dominance criteria can be extended in the following way: we create a convex combination of the distribution functions such that it dominates an alternative in a certain stochastic dominance sense. Then the dominated alternative can be eliminated from the alternative set, thus in every step the size of the set can be reduced (Drynan, 1986).

\section{Generalized stochastic dominance}

The generalized stochastic dominance criterion is a stronger method than the above ones because the risk aversion and the utility function are both taken into account (Goh et al., 1989). First the interval $I_{r}$, which contains the value of the risk aversion with great probability, is fixed. Then the utility function has to be estimated with the help of the absolute risk aversion $r_{a}$. Based on the approximated utility function first and second order stochastic dominance relations are tried to be found.

This method was simplified by Hardaker et al. (2004) in a very smart way. By the Bernoulli principles the utility function $U$ can be regarded as a function of two variables as it depends on the risk aversion as well:

$$
U(x, r)=\int U(t, r) \cdot f(t) d t .
$$

From this we get $C E(x, r)=U^{-1}(x, r)$. Supposing a negative exponential utility function both $U$ and $U^{-1}$ can be estimated as:

$$
U\left(x, r_{a}\right)=\sum_{i}\left(F_{i+1}-F_{i}\right)\left[1-\frac{\left(\exp \left(-r_{a} x_{i}\right)-\exp \left(-r_{a} x_{i+1}\right)\right)}{r_{a}\left(x_{i+1}-x_{i}\right)}\right] \quad\left(r_{a} \in I_{r}\right)
$$

and

$$
C E=\frac{-\ln \left[1-U\left(x, r_{a}\right)\right]}{r_{a}} \text {. }
$$

If we illustrate the values $C E$ with respect to the risk aversion, the graph lying the highest points the most preferable alternative. In the case the graphs are crossing each other, we can define the intervals of $r_{a}$ in which an alternative is better than another.

\section{Materials and methods}

Crop and wheat production data (1951-90) in four Hungarian regions (Hajdú, Bács, Fejér and Győr-Moson-Sopron megye) were considered. The data were fitted by logistic regression function of form $f: x \mapsto f(x)=p_{1}+\frac{p_{2}}{1+\exp \left[-p_{3}\left(x-p_{4}\right)\right]}$ with parameters $p_{1}, p_{2}, p_{3}, p_{4}$. (It was quite reasonable to use logistic regression because in Hungary 
there was a meaningful change in both technology and species at the beginning of the 70s.) Then the Phillips-method was applied for making the data comparable.

Based on experts' estimations first the subjective mean and the standard deviation $\left(E_{\mathrm{s}}, D_{\mathrm{s}}\right)$ were elicited with triangular distribution estimation.

Secondly, with the residuals of the regression $\varepsilon_{i}$ the data were corrected such as $\hat{y}_{i}=f\left(x_{\text {curr }}\right)+\varepsilon_{i}$.

Thirdly, with equal weights $p_{i}\left(\sum_{i} p_{i}=1\right)$ the mean and standard deviation $(E, D)$ were calculated from which the comparable data $Y_{i}$ with $E\left(Y_{i}\right)=E_{\mathrm{s}}$ and $D\left(Y_{i}\right)=D_{\mathrm{s}}$ were obtained.

The data of time interval (1951-90) were splitted into three parts: 1951-70, 1961-80, 1971-90. Observing the corn yield we recognized that beside the yield loss caused by the Hungarian political situation at the end of the eighties, the deviation of the yield started to become greater yet at the beginning of the eighties. There was a heavy corn yield loss in 1990, thus we investigated the problem for corn in two ways:

- with tree times twenty years (1951-70, 1961-80, 1971-90) and

- eliminating the year 1990, with a shortened data series (1951-70, 1961-80, 1971-89).

During the survey the most general negative exponential utility function was used.

The $E$, $V$-efficiency criterion, the criterion based on the utility function and stochastic dominance rules were applied to the three time intervals in order to find out, how the risk of production was changed between 1951 and 1990.

\section{Results}

\section{Corn and risk production in four Hungarian regions between 1951-1990}

In Hungarian agricultural activity the risk of crop and wheat production has a significant role. With climate change the risk is suspected to be increasing. In what follows we show with the above introduced methods that the risk of corn and wheat production was increasing in four Hungarian regions between 1950 and 1990, partly independently from the risk aversion of the DM. In some regions, moreover, the increase is quite high and became quicker.

Figure 2 shows the corn (left) and wheat (right) production data $Y_{i}$ of four Hungarian regions obtained by the Phillips-method 1951-1990 (kg/ha). As the data are yet comparable, we can deduce that the occurrence of some extreme values at the end of the 80 s means that the safety of the corn and wheat yield has explicitly decreased. The deviance at the end of the 80 s is generally less for the wheat production, though it is evident, too. This leads us to suspect that the risk has increased for the production of both plants. 

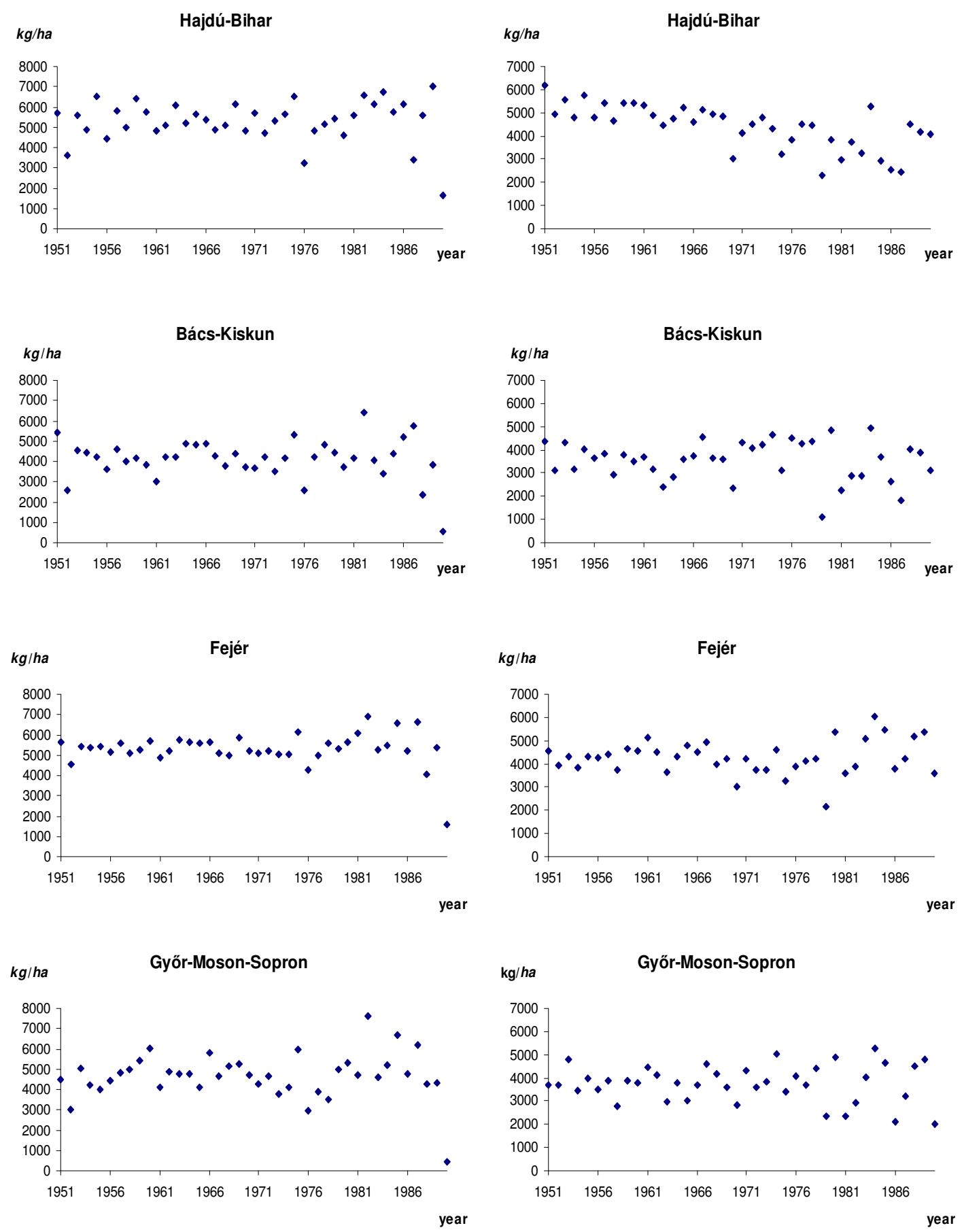

Figure 2. The corn (left) and wheat (right) production data $Y_{i}$ of four Hungarian regions obtained by the Phillips-method 1951-1990 ( $\mathrm{kg} / \mathrm{ha}$ ) 


\section{The change of risk of corn production in four Hungarian regions between 1951-1990}

\section{Subjective distribution functions}

Using the data obtained by the Phillips-method on the basis of experts' estimations we defined the subjective distribution functions for the four Hungarian regions and for the time intervals 1951-70, 1961-80, 1971-90 (Fig. 3).

In Bács-Kiskun, while the expectation was decreasing in time, the deviation was increasing (the subjective distribution function was shifted left, its slope has increased). For the other regions the change is not so evident.
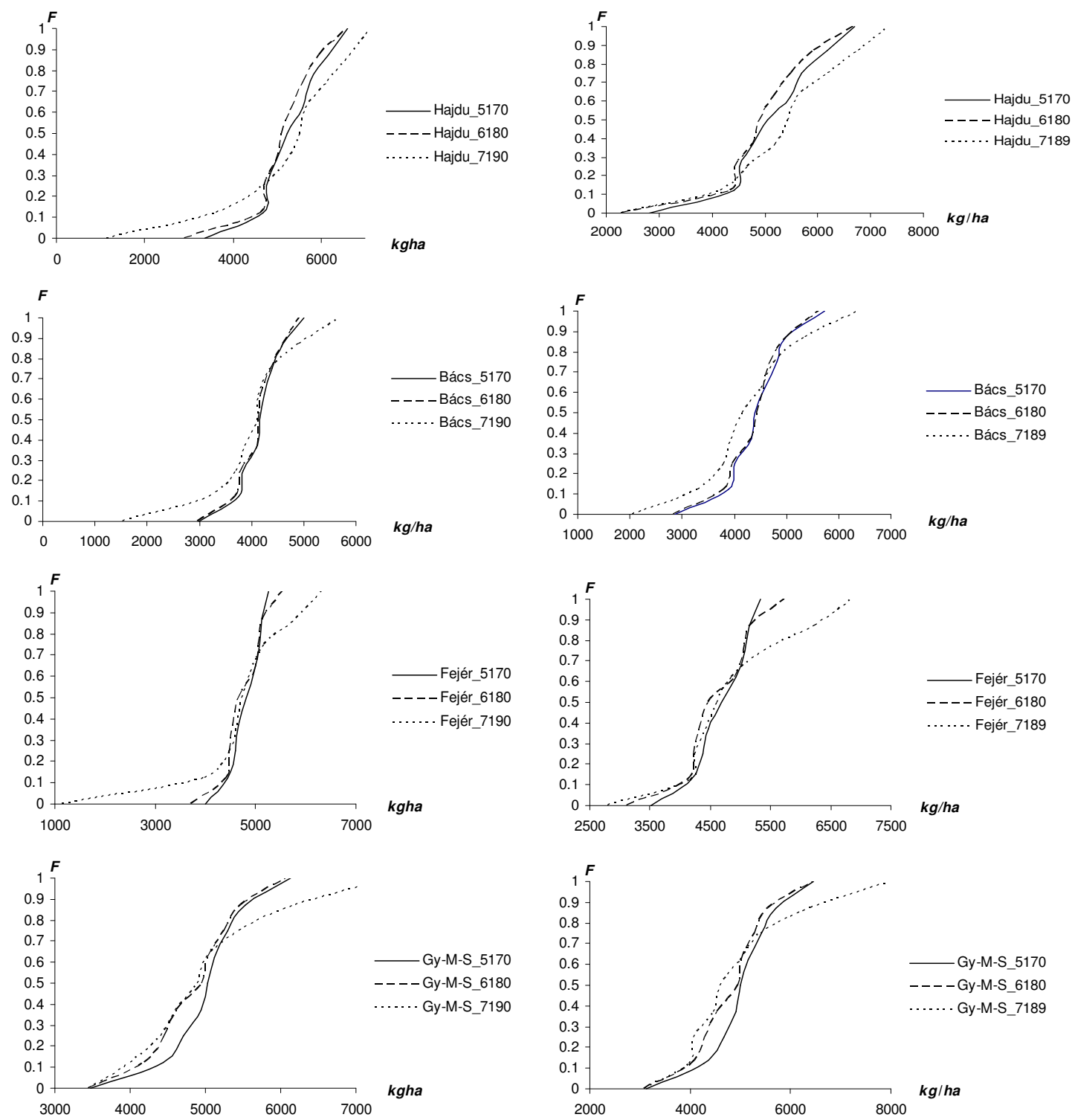

Figure 3. Subjective distribution functions for corn production in four Hungarian regions and three time intervals 1951-1970, 1961-1980, 1971-1990 (kg/ha) The same is for truncated data where the last time series is 1971-1989 (right). 
Stochastic dominance, E, V efficiency and the criteria based on the utility function

In Bács-Kiskun and also in Fejér the E,V-efficiency method gives the same result for the whole time intervals. We can see namely, that the points with respect to the last time interval (1971-90) denoted by H7 (Fig. 4, left) have both the other points H5 and H6 (with respect to 1951-70 and 1961-80, resp.) in their 'north-west' quadrant. (The last time interval involves the greatest risk.) For the other regions and for Fejér with the truncated data the E,V-efficiency method does not make any ordering. (Truncated data do not contain the very extreme year 1990 and thus H7 is for 1971-1989 instead of 1971-1990.)
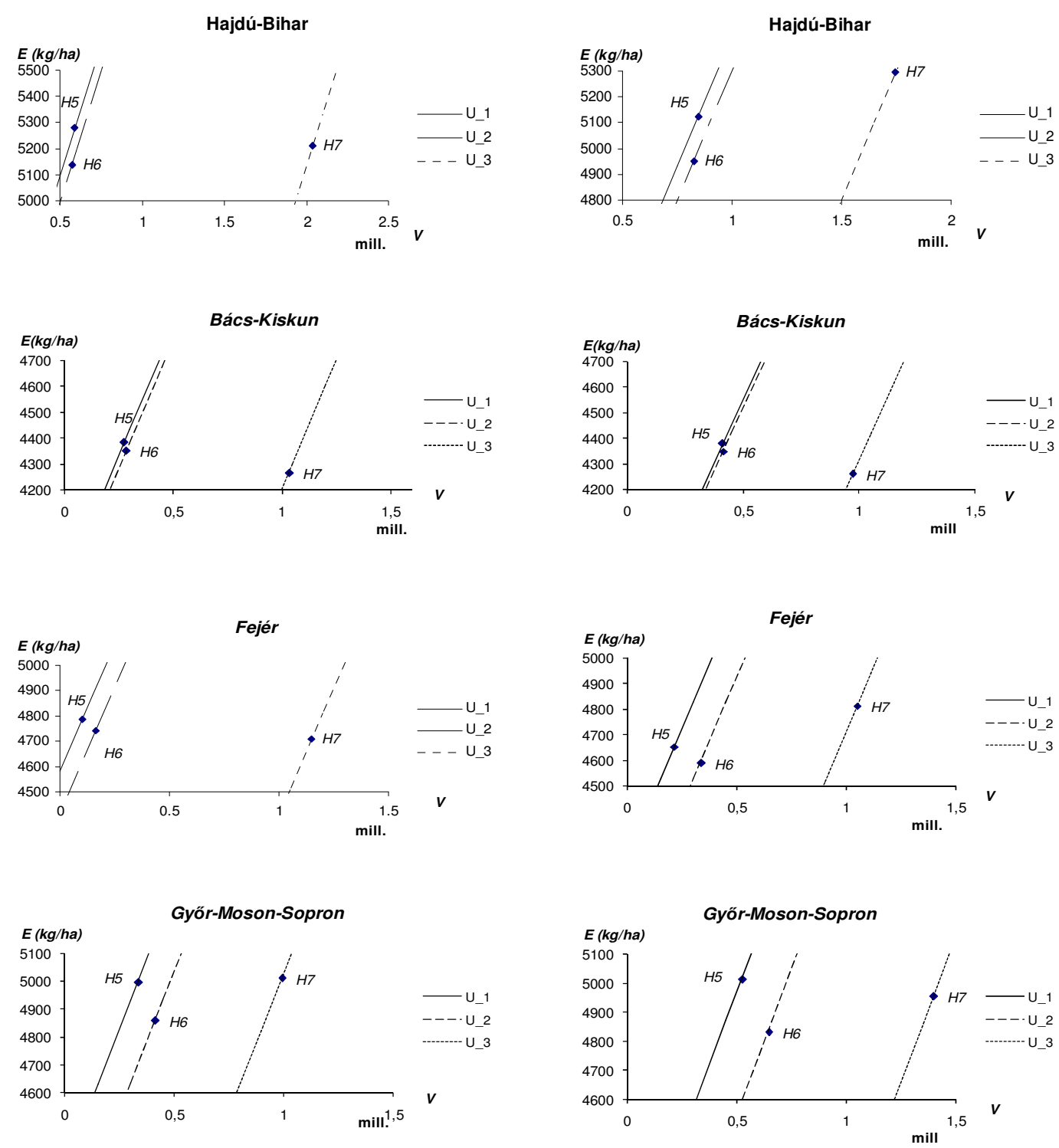

Figure 4. E, V-efficiency and indifference curves for corn production in four Hungarian regions. H5 is for 1951-1970, H6 is for 1961-1980, H7 is for 1971-1990 (left). The same is for truncated data where H7 is for 1971-1989 (right) 

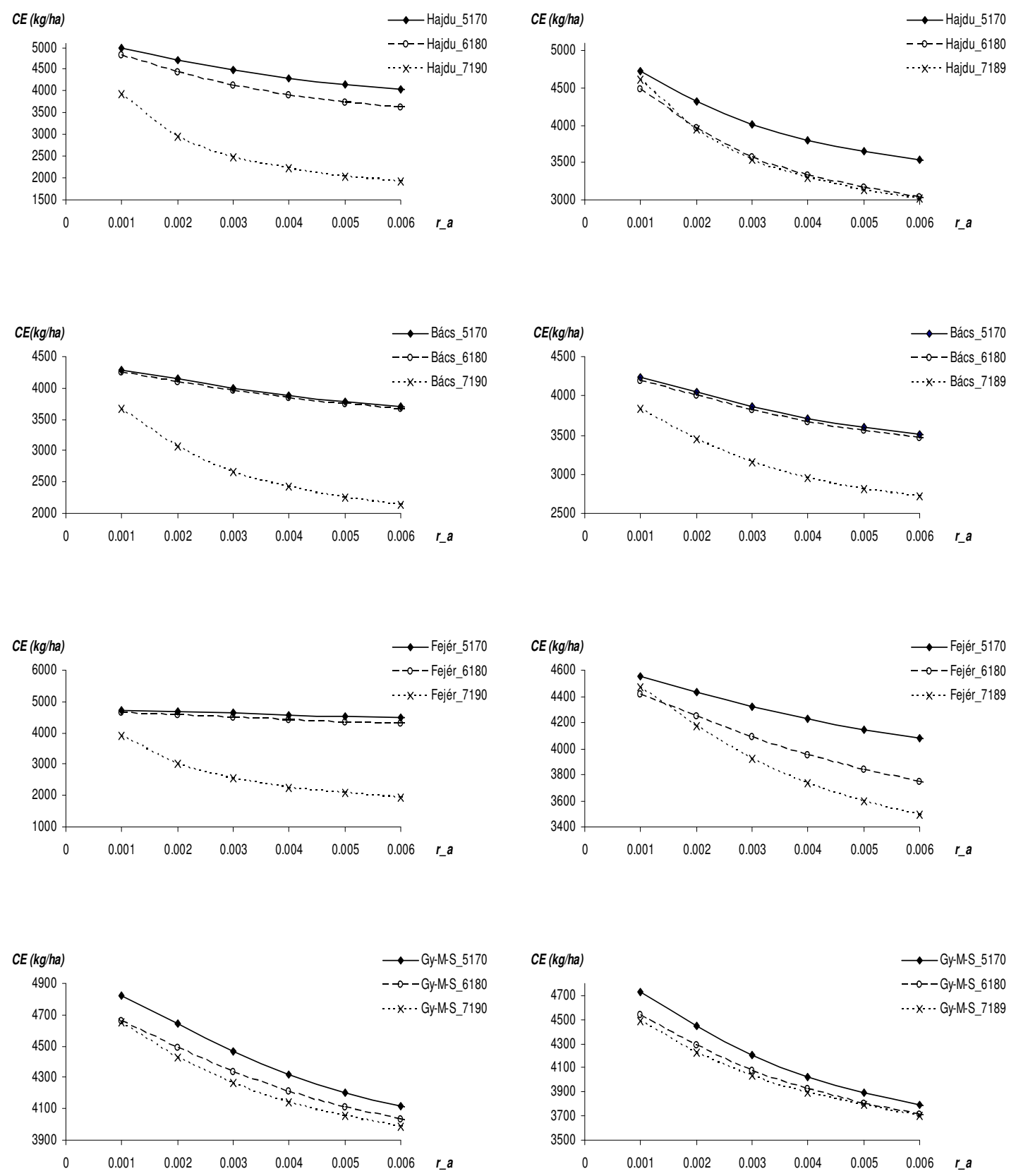

Figure 5. Stochastic efficiency for corn production in four Hungarian regions with respect to 1951-1970, 1961-1980, 1971-1990 (left). The same is for truncated data when instead of 19711990 we have 1971-1989 (right). 
Together with $E, V$-efficiency the linear functions were also defined for absolute risk aversion value $r_{a}=0.004$ and for three fixed certainty equivalent ( $C E$ ) values (Fig. 4 and 5). In every case we got that the situations become worse with time. The disadvantage of the method based on utility criterion is, however, that it makes an ordering for fixed absolute risk aversion, only. For more information we should call for the more general stochastic efficiency criterion.

\section{Stochastic efficiency}

In Fig. 5 (left) we consider the graphs of the values $C E$ with respect to the risk aversion. The curves that are lying the higher are the more preferable alternatives with the less risk. Comparing the time intervals 1951-70 and 1961-80, applying the stochastic efficiency criterion we obtained suggestively that the risk of corn production has increased in all the four regions, independently from the rate of absolute risk aversion. (The graphs of the earlier time series are lying higher.) The risk of time interval 1971-90 has increased even more in all regions except Györ-Moson-Sopron, especially for greater $r_{a}$ values.

We can ask whether this risk increase is caused only by the heavy yield loss of 1990 . Using the truncated data we can see that the rate of risk increase is less, but evident, especially for greater $r_{a}$ values.

For the truncated data we calculated again the $C E$ values depending on the absolute risk aversion $r_{a}$ Fig. 5 (right). We got that the time series with the less risk was the earliest (1951-1970). In Hajdú-Bihar and Fejér the risk increase holds only for $r_{a}>0.002$. This fact, however, does not make the importance of the objective warning less serious. The risk increase was the greatest in Bács-Kiskun and the less in GyörMoson-Sopron, but the fact of risk increase is obvious everywhere.

\section{The change of risk of wheat production in four Hungarian regions, 1951-1990}

\section{Subjective distribution functions}

First the subjective distribution functions were elicited for the four regions and for the three times series 1951-70, 1961-80, 1971-90 with the data obtained by the Phillipsmethod on the basis of experts' estimations (Fig. 6). (In the case of wheat the use of truncated data was not reasonable, because the yield loss of the most extreme year 1979) was not as extreme as it was for corn production.) Note that the increase of deviation can be seen in every region which indicates a possible risk increase.

\section{Stochastic dominance, E, V efficiency and the criteria based on the utility function}

The most evident risk increase of wheat production was in Hajdú-Bihar. The subjective distribution functions are ordered here pointwise (the earlier time intervals dominate the later ones in first-degree sense). The same can be proved with the $E, V$ efficiency method, though with this method we get no ordering for the time intervals in the other three regions. The criterion based on the utility function gives the same ordering for the three time intervals in all regions except Fejér. This proves the risk increase obviously, though, only for the fixed $r_{a}=0.004$ value (Fig. 7). 

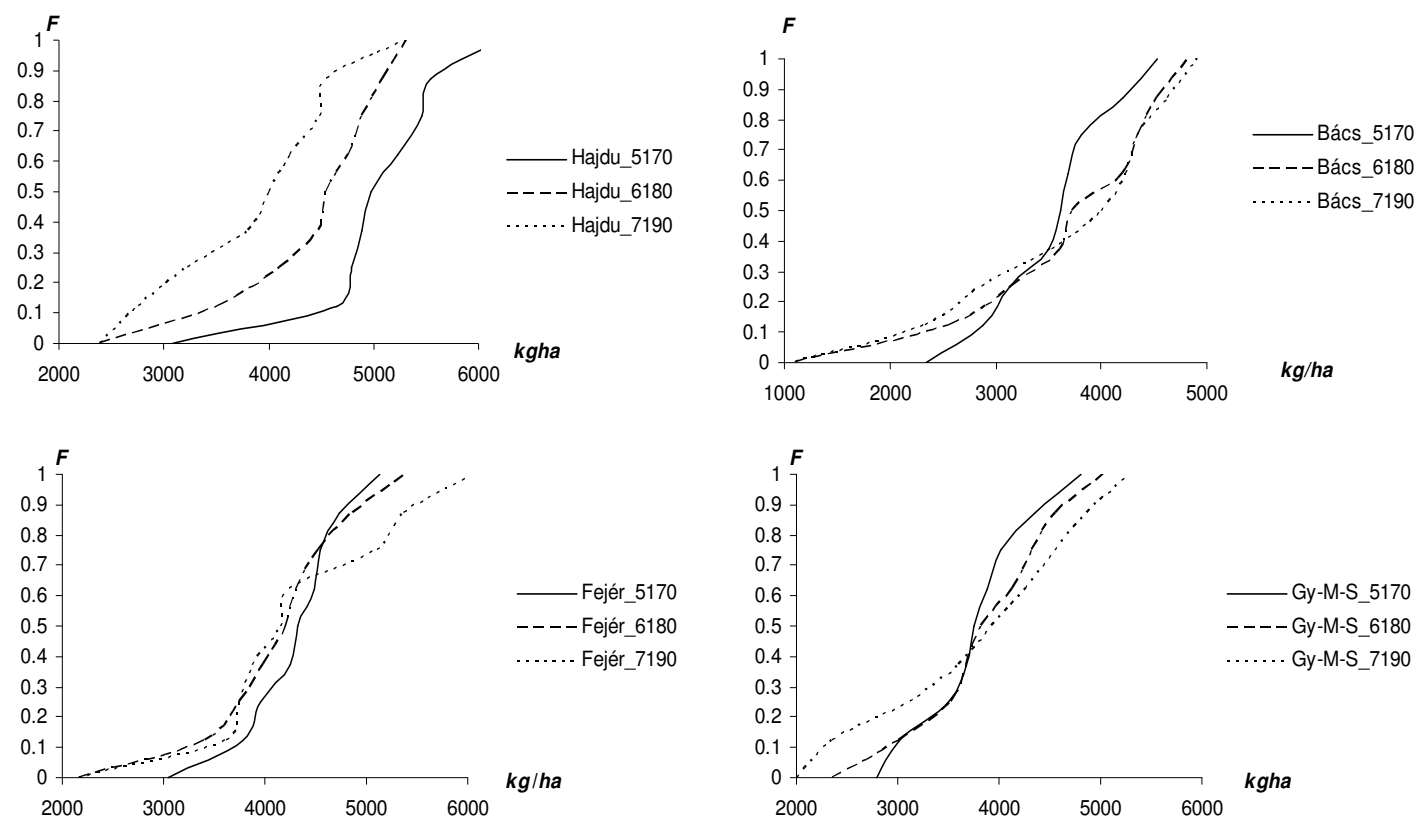

Figure 6. Subjective distribution functions for wheat production in four Hungarian regions and three time intervals 1951-1970, 1961-1980, 1971-1990 ( $\mathrm{kg} / \mathrm{ha})$
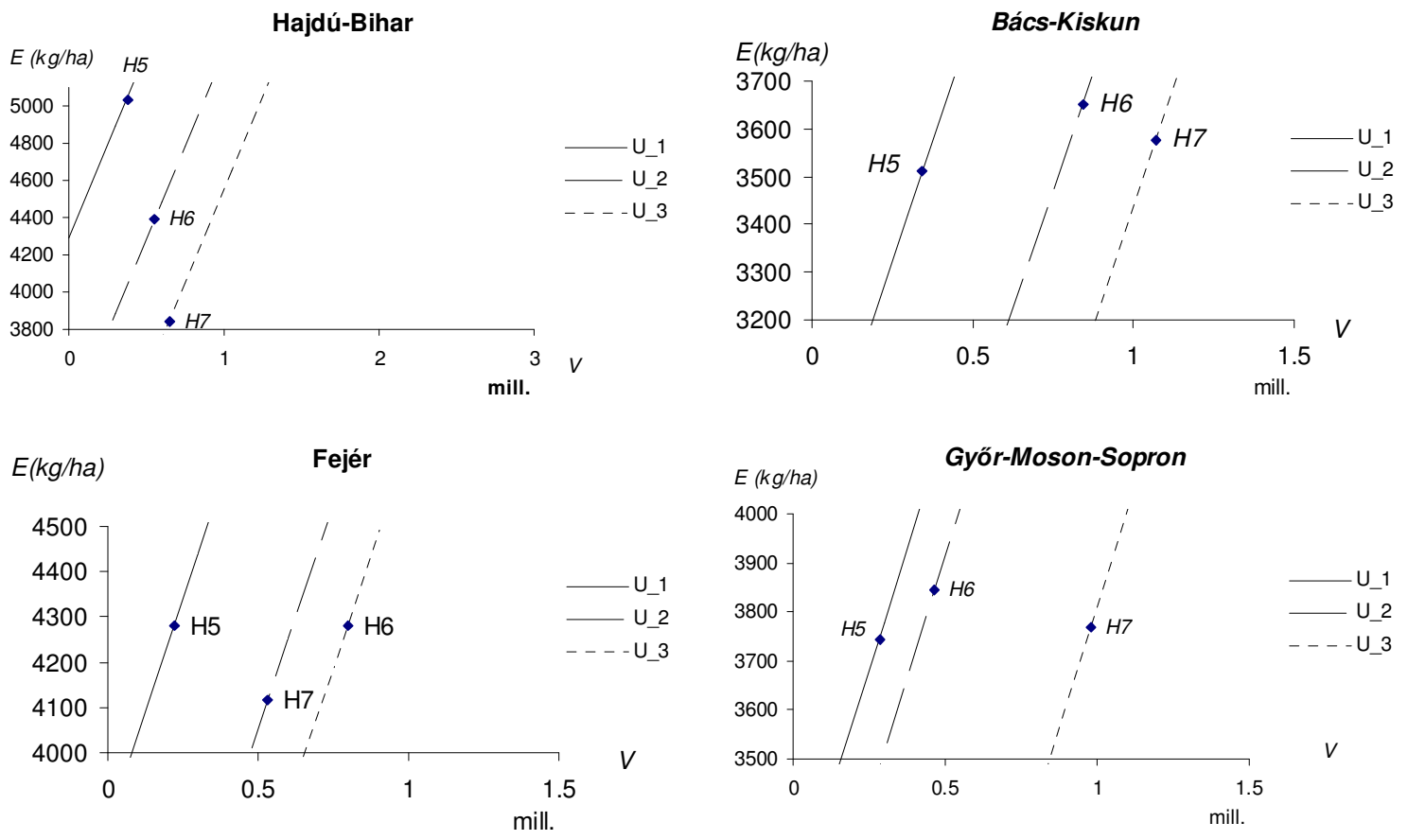

Figure 7. E, V-efficiency and indifference curves for wheat production in four Hungarian regions. H5 is for 1951-1970, H6 is for 1961-1980, H7 is for 1971-1990. 


\section{Stochastic efficiency}

Comparing the time intervals 1951-70 and 1961-80, applying the stochastic efficiency criterion we proved that the risk of wheat production has increased in all the four regions, but Fejér, independently from the rate of absolute risk aversion $r_{a}$ (Fig. 8). In Fejér the less risky interval was 1951-70 and the most risky one was 1961-80 for almost the whole domain of $r_{a}$. The risk increase was the greatest for 1971-90 only if $r_{a}>0.014$. In contrary to the case of corn production, the rate of increase became greater only in Györ-Moson-Sopron, but independently from $r_{a}$.
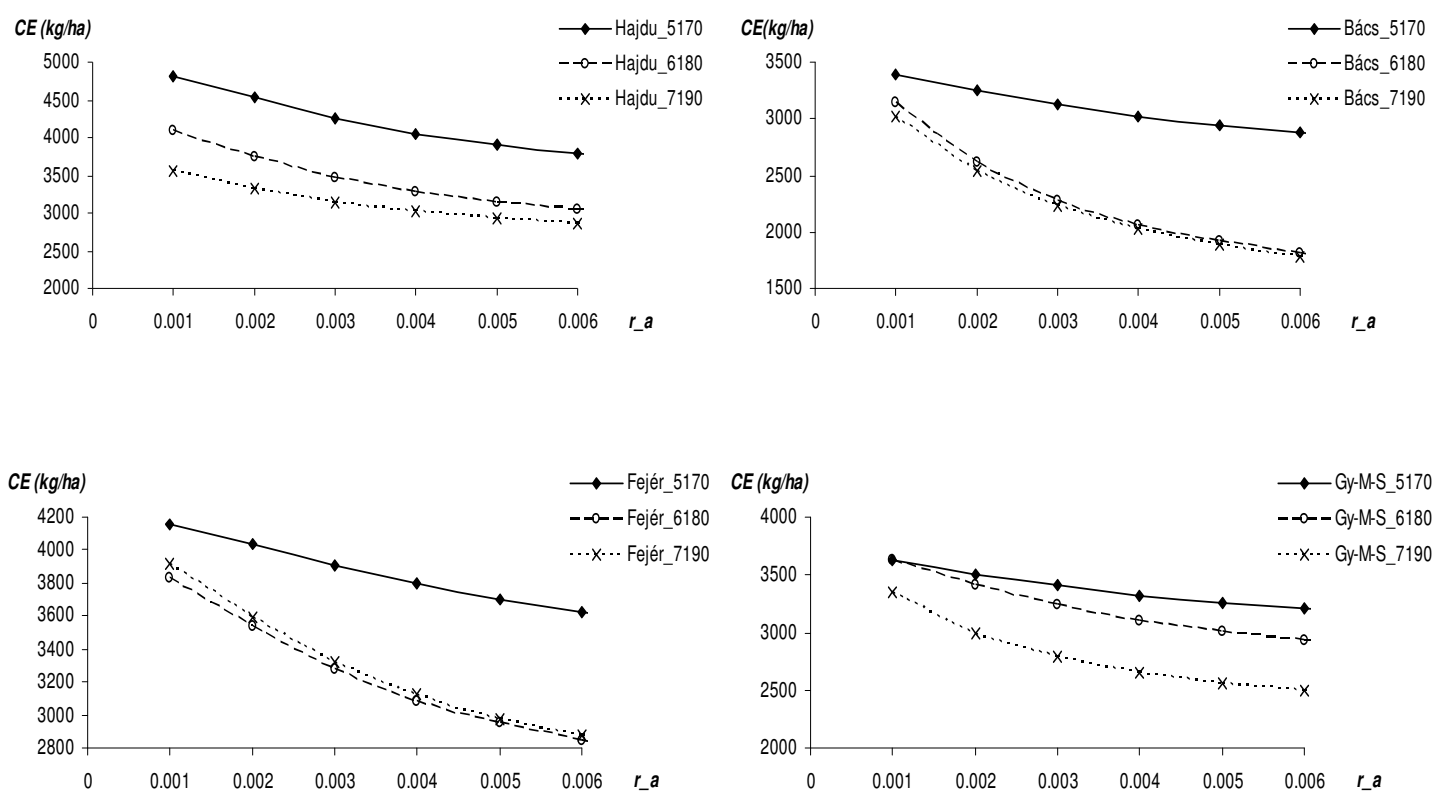

Figure 8. Stochastic efficiency for wheat production in four Hungarian regions with respect to 1951-1970, 1961-1980, 1971-1990

\section{Discussion}

After having reviewed some recent methods of risk assessment we introduced some case studies. Crop and corn production was investigated between 1951 and 1990. We have cut the long time series into three shorter ones in order to be able to compare them from the production risk's aspect. The risk increase has been proved for all the examined regions in Hungary, the differences were in the rate of them, only. This approach is aimed, above all, to introduce the methodology of risk assessment; nevertheless, the result of it draws our attention to the importance of risk increase in agriculture. Further researches are planned to find the reasons of risk increase based on historical data and to investigate the expected risk caused by climate change based on GCM's.

Acknowledgements. Our work was supported by NKFP-B3-2006-0014, OTKA T042583 tender and the Jedlik Ányos NKFP6-00079/2005 program. 


\section{REFERENCES}

[1] Anderson, J.R., Hardaker, J.B. (2003): Risk Aversion in Economic Decision Making: Pragmatic Guides for Consistent Choice by Natural Resource Managers. - In: Wesseler, J., Weikard, H-P., Weaver, R. (eds) Risk and Uncertainty in Environmental and Natural Resource Economics. - Edward Elgar, Cheltenham, pp. 171-188.

[2] Anderson, J.R., Dillon J.L. (1992): Risk Analysis in Dryland Farming Systems. Farming Systems Management Series No. 2, FAO, Rome

[3] Anderson, J.R., Dillon, J.L., Hardaker, J. B. (1977): Agricultural Decision Analysis. Iowa State University Press, Ames

[4] Arrow, K.J. (1963): Social Choice and Individual Values. - 2nd edn. Wiley, New York

[5] Arrow, K.J. (1965): Aspects of the Theory of Risk-Bearing. - Yrjö Jahnssonin Säätiö, Academic Bookstore, Helsinki.

[6] Barry, P.J. (1984): Risk Management in Agriculture. - Iowa State University Press, Ames

[7] Bell, D.E. (1988): One Switch Utility Functions and measure of Risk. - Management science 34: 1416-1434.

[8] Clemen, R.T. (1996): Making Hard Decisions: An Introduction to Decision Analysis. 2nd edn. Duxbury Press, Belmont, California

[9] Dillon, J.L. (1971): An Expository Review of Bernoullian Decision Theory: Is Utility Futility? - Review of Marketing and Agricultural Economics 39: 3-80.

[10] Drynan, R.G. (1986): A Note on Optimal Rules for Stochastic Efficiency Analysis. Australian Journal of Agricultural Economics 30: 53-62.

[11] Edwards, W. (ed.) (1992): Utility Theories: Measurements and Applications. - Kluwer, Boston, Mass.

[12] Eeckhoudt, L., Gollier, C. (1996): Risk: Evaluation, Management and Sharing. Harvester Wheatsheaf, Hemel, Hempstead.

[13] Farquahar, P. H., Nakamura, Y. (1987): Constant Exchange Risk properties. - Operations Research 35:206-214.

[14] Freund, R. J. (1956): The introduction of risk into a programming model. - Econometrica 24: 253-261.

[15] Goh, S., Shih, C.-C., Cohran, M.J., Raskin, R. (1989): A Generalized Stochastic Dominance Program for the IBM PC. - Southern Journal of Agricultural Economics 21: 175-182.

[16] Gregory, G. (1988): Decision Analysis. - Plenum, New York

[17] Halter, A.N., Dean, G.W. (1971): Decisions under Uncertainty with Research Applications. - South-Western Press, Cincinnati

[18] Hamal, K.B., Anderson J.R. (1982): A note on decreasing absolute risk aversion among farmers in Nepal. - Australian Journal of Agricultural Economics, 26: 220-225.

[19] Hardaker, J.B. (2000): Some Issues in Dealing with Risk in Agriculture. - Working Paper Series in Agricultural and Resource Economics No 2000-3, GSARE, University of New England, Armidale, NSW.

[20] Hardaker, J.B., Huirne, R.B.M., Anderson, J.R., Lien, G. (2004): Coping with Risk in Agriculture. - 2nd edn. CABI Publishing, Wallingford-Cambridge

[21] Just, R.E. (2003): Risk Research in Agricultural Economics: Opportunities and Challenges for the next Twenty-Five Years. - Agricultural Systems 75: 123-159.

[22] Knight, F.H. (1933): Risk, Uncertainty and Profit. - Houghton Mifflin, Boston, Mass

[23] Lindley, D.V. (1985): Making Decisions. - 2nd edn. Wiley, London

[24] Meyer, J. (2001): Expected Utility as a Paradigm for Decision Making in Agriculture. In: Just and Pope pp. 3-19.

[25] Nakamura, J. (1996): Sumex Utility Functions. - Mathematical Social Sciences 31: 3947.

[26] Pannell, D.J., Malcolm, B., Kingwell, R.J. (2000): Are we risking too much? Perspectives on Risk in Farm Modelling. - Agricultural Economics 23: 69-78. 
[27] Phillips, J.B. (1971): Statistical Methods in Systems Analysis - In: Dent, J. B., Anderson, j. R. (eds) Systems Analysis in Agricultural Management. Wiley, Sydney, pp. 34-52.

[28] Pratt, J.W. (1964): Risk Aversion in the Small and in the Large. - Econometrica, 32: 122136.

[29] Pratt, J.W., Raiffa, H., Schlaifer, R. (1995): Introduction to Statistical Decision Theory. MIT Press, Cambridge, Mass.

[30] Pratt, J.W., Raiffa, H., Schlaifer, R. (1995): Introduction to Statistical Decision Theory. MIT Press, Cambridge, Mass.

[31] Quiggin, J., (1993): Generalized Expected Utility Theory: The Rank Dependent Model. Kluwer, Boston, Mass.

[32] Raiffa, H. (1968): Decision Analysis. - Addition-Wesley, Reading, Mass

[33] Robison, L.J., Barry, P.J. (1987): The Competitive Firm's Response to Risk. Macmillan, New York

[34] Saha, A. (1993): Expo-power Utility: a Flexible Form for Absolute and Relative Risk Aversion. - American Journal of Agricultural Economics 75: 905-913.

[35] Savage, L.J. (1954): Foundations of Statistics. - Wiley, New York

[36] Schlaifer, R. (1959): Probability and Statistics for Business Decisions Analysis. McGraw-Hill, New York

[37] Schlaifer, R. (1969): Analysis of Decisions under Uncertainty. - McGraw-Hill, New York

[38] Smith, J.Q. (1988): Decision Analysis: A Bayesian Approach. - Chapman and Hall, London

[39] Smith, J.Q., Mandac, A. M. (1995): Subjective vs Objectice Yield distributions as Measures of production Risk. - American Journal of Agricultural Economics 77: 152161.

[40] Spetzler, C.S., Staël von Holstein, C.-A.S. (1975): Probability Encoding in Decision Analysis. - Management Science 22: 340-352.

[41] Wright, G., Ayton, P. (eds) (1994): Subjective Probability. - Wiley, Chichester 